\title{
Research on the Change of the Rural Medical and Health Services System in Jilin
}

\author{
Yafeng Zhou \\ School of Jilin Agricultural University, Jilin 132000, China \\ wmh@ccut.edu.cn
}

\begin{abstract}
This article discussed the relevant problems of serving development of rural medical and health services system of Jilin province mainly. On the basis of analyzing Jilin's current rural medical and health services system current situation and question, it stated briefly the service function of the rural medical and health services system. It analyzed that develops feasibility and meaning of the rural medical and health services system. The paper also put forward the suggestion on the operating mode of the rural medical and health services system. Finally, it analyzed the supporting policy that influences the development of the rural medical and health services system.
\end{abstract}

Keywords: the rural medical and health services system; operating mode; rural community.

\section{Introduction}

To solve the farmers' problem of "doctor expensive and medical difficult" is a crucial element to solve the "issues of agriculture, farmers and rural area" and realize the coordinated development of urban and rural areas, building a socialist harmonious society. Although after the reform and opening up China has accelerated the rural economic development, and increased income level of farmers, the level of health protection of farmers ill-matched with the economic development and our rural medical treatment and public health insurance are still behind of the level of urban health medical. In China, $70 \%$ of the rural population only takes up 30\% of security medical resources, but $30 \%$ of the urban population have already taken up $70 \%$ of medical resources.

Under the background of building a harmonious society, the new rural cooperative medical system is a kind of preferential agricultural policy applied by the Government to continually address the “Three Rural Issues". In 2002, Chinese Central Commission of Chinese Communist Party and State Councils Decision about Strengthening Rural Health Work clearly pointed out that "China should gradually establish a serious sickness dominated new rural cooperative medical system”. Since 2003, there begins some experiments in some selected some counties. The new rural cooperative medical system is a major component of our Chinese rural health care system. It is organized, guided and supported by the government, referring to a kind of farmers' independent system in which the farmers can voluntarily participate. And by raising fund through multiple channels including the individuals and governments, it takes serious illness as priority as a whole.

By 2010, the National Farmer Participation NCMS number reached 835 million, the participation rate reached to $95 \%$. As the main body of the rural health protection, the new rural cooperative medical care reflects the status of implementation of rural health insurance system. Of course, to give a comprehensive measure on health insurance in rural areas, we cannot ignore other supplementary developments such as the rural public health services and medical assistance in rural parts.

Agricultural population proportion is large in Jilin Province, the success and the sustainable development of the new rural cooperative medical systems is close to the success of the rural economy and social stability and the harmonious development of rural economy and society. Therefore, it is necessary for Jilin province to give a comprehensive summary to the development of the new rural cooperative medical care system, and make a comprehensive analysis for its running condition, to understand the overall status of new rural cooperative medical care system and its main problems in Jilin province. Then suggestions for the development of new rural cooperative medical care system can be put forward, it has profound practical significance to the rural economic and social harmony, stability and sustainable development. 


\section{The rural health service system development process in Jilin province}

Jilin province, a typical agricultural province, is located in the center of northeast of China region, north Korea, South Korea, Japan, Mongolia and Russia, it is one of the main granary in China and an important old industrial base. According to the sixth national population census data, the population of permanent residents in Jilin province is 27.4528 million people, including 14.6482 million urban population, accounting for $53.36 \%$; and 12.8046 million rural population, accounting for $46.64 \%$. In health care, because of the rural population is mainly participate in the new rural cooperative medical care, nearly half the population in Jilin province participate in the new rural cooperative medical care, this allows the health care industry in Jilin province presents different characteristics from other provinces. The operation condition of the new rural cooperative medical care system in Jilin province is related to the further perfection and development of the new rural cooperative medical care system, it plays an important role for promoting the construction of new socialist countryside.

In 2003, as one of China's first four provinces that new rural cooperative medical care, take the lead in carrying out the new rural cooperative medical care pilot work, established for the new rural cooperative medical care system has accumulated rich experience.

In 2003, Jilin province as one of China's four new rural cooperative medical care pilot province took the lead in carrying out the new rural cooperative medical care pilot work, has accumulated rich experience in establishing the new rural cooperative medical care system.

In 2005, on the basis of expanding the pilot range, Jilin province first carried out the pilot project of the comprehensive arrangement for chronic disease, expand the personnel benefit of new rural cooperative medical care.

In 2006, Jilin province the first unified the compensation scheme of new rural cooperative medical care in hospital in the entire province, took the lead to standardize the province's new rural cooperative medical drugs and diagnosis and treatment project directory, narrowed the differences between the areas, fully embodied the fairness of the new rural cooperative medical security system.

In 2007, Jilin province took the lead in realizing a complete coverage of the new rural cooperative medical care system, let the farmers of the province's 67 counties can enjoy the benefits of new rural cooperative medical policy.

In 2008, Jilin province took the lead in establishing a relatively uniform compensation model, a standardized mechanism to return money and referral system, reform and improve the management system and operational mechanism which are not fit for the real-time settlement and reimbursement system. It maximized convenient to farmers' medical treatment, submit the expense account, effectively reduced the economic burden of the farmers who had participated in the new rural cooperative medical care system.

In 2009, Jilin province took the lead in the province within the scope of the network management of the new rural cooperative medical care, can not only improve the new rural cooperative medical service ability and the management level, but also improve the working efficiency.

In 2010, Jilin province took the lead in realizing a complete coverage of comprehensive arrangement for outpatient service. Farmers receive outpatient service in the village medical institutions can also submit an expense account. It greatly improved the new rural cooperative medical care system benefited range. It can guide famers to treat early, avoid ailment turn into a serious illness and brings to the farmers' economic burden. In that year newborn babies can also be brought into the new rural cooperative medical coverage, made newborns can also enjoy the new rural cooperative medical care to ensure treatment.

In 2011, Jilin province expanded the rescue scope of major disease, increased new rural cooperative medical reimbursement compensation levels of 20 major diseases, effectively relieved cases that famers become poorer and poorer by the suffering from a serious illness.

In 2012, there are still a lot of new breakthroughs and innovations on the construction of the new rural cooperative medical system in Jilin province. One is that the new rural cooperative medical financing level was improved, the new rural cooperative medical compensation scheme was optimized, and it benefits farmers more. Secondly, eight kinds of diseases of the new rural cooperative medical reimbursement ratio increased to $70 \%, 23$ kinds of major diseases reimbursement ratio 
increased to $60 \%$, common disease reimbursement ratio increased to $50 \%$, hospital compensation top line up to 80000 yuan.

In 2013, new breakthroughs were made in the treatment of serious diseases, province public finance provided 11 yuan per person for farmers who had participated in the new rural cooperative medical care system, to explore how to establish a new rural cooperative medical supplementary insurance system cooperated with commercial insurance company which is suitable for Jilin province.

In 2014, new progress was made in the new rural cooperative medical information network construction in Jilin province. On the basis of "all-in-one-card" system, Jilin province successfully achieved the connection with the country's new rural cooperative medical information platform, laid the network foundation for instant settlement between provincial reimbursement, effective regulation, and information sharing of the new rural cooperative medical care.

In 2015, the new rural cooperative medical care payment reform has achieved remarkable achievement, effective controlled unreasonable increases in medical costs. The comprehensive reform pilot work was successfully launched at medical establishments in provinces, cities, countries and townships. It can ensure the safe and effective operation of the new rural cooperative medical fund, effectively improve the using efficiency of the new rural cooperative medical fund.

\section{Summary}

Studies have shown that infrastructure construction condition improved consumedly in Jilin province from the 21th century. The training to the community health service personnel has got good effect. The service mode and content of the community health service has successfully changed. The work load of the community health service centers and stations has increased greatly. The mean income and the profit and payout balance of the community health service centers and stations has increased greatly. However, several defects are detected in the study. The installation of the division is not ideal. Not sorting out the community health service troops according to the demand of the community health service. And the capability of the community health service troops is not ideal. Some public health services have not been carried out enough. The income structure of the community health service centers and stations lack of long-term and lasting reimbursement mechanism is unreasonable.

To improve the rural medical and health services system at the new situation of market economic development, the policy options should put priorities to following areas: to strengthen government responsibility for people's health, to optimize rural health system, and to ensure the adequate public health provision, so as to protect rural people's rights in health and health service utilization. Governmental coordination of establishing a balancing mechanism between different plans is important to enhance equity between different plans and members within and outside the mechanism. The quality, efficiency and equity of Jilin's rural medical and health services system are not satisfactory. It could be attributed to insufficient input of medical resources to the rural sector, lack of medical security system in rural areas, and to the absence of government and market function on the medical service sector due to undeveloped medical management system. Although the disintegration of original rural community medical scheme was heavily influence by the economic reform, its technical design was also unsustainable, limiting its survival and development under certain historical environment. Once its dependent institutional context changed, its design defects were completely exposed, such as the participatory model, the average contribution level, the compensatory model and the payment method.

From above of all, rural community health service has the feasibility of carrying out. The experience is worth applying and spreading: to spread the propaganda of community health service, expedite the transformation of health center in villages and towns to the community health service center in deed, strengthen the whole medical knowledge training to enhance the capability of the community health service troops that can lay a personnel foundation to the community health service. 


\section{Acknowledgments}

This paper is the research project of Jilin province rural community health service system constr uction in Jilin province. (item number 20140418062FG)

\section{References}

[1]. Jiancong Wang: Research on China's rural basic health care system (Doctor degree, Dongbei University of Finance and Economics, China 2011). p. 13-15

[2]. Chuanjun Gu: The research on new rural cooperative medical system in China (Master degree, Southwestern University of Finance and Economics, China 2007). p. 19-25

[3]. Guoping Yang: Research on sustainable development of new rural cooperative medical schemes of China (Doctor degree, Fudan University, China 2008). p. 28-35

[4]. Yanli Liu: The change of rural health care system in China: historical review and theoretical anaslysis(Master degree, Shandong University, China 2007). p. 23-30

[5]. Jianping Zhang: Study on the cooperative medical service system in china's rural areas (Doctor degree, Northwest A\&F University, China 2006). p. 75-82 